\title{
Sociodemographic Situation of Elderly Affected by Systemic Arterial Hypertension
}

\author{
Gláucia de Souza Abreu Alencar ${ }^{1}$, \\ Betânia Maria Pereira dos Santos²,
} Maria do Carmo Andrade Duarte de Farias ${ }^{3}$, Gustavo de Alencar Figueiredo ${ }^{4}$, Anahi Cezar de Lima Lins ${ }^{5}$, Heloisa Helena Alves Andrade ${ }^{5}$, Nívia Maria da Silva ${ }^{5}$, Jessika Lopes Figueiredo Pereira ${ }^{6}$, Anne Milane Formiga Bezerra ${ }^{11}$, Sayonara Mary Vieira de Sá ${ }^{8}$, Kamila Nethielly Souza Leite ${ }^{9}$, Danilo Cleber N. de Lima ${ }^{10}$, Katiana Macêdo Duarte ${ }^{10}$, Alessandro Leite Cavalcanti ${ }^{11}$

\section{Abstract}

Objective: To investigate the occurrence of systemic hypertension in elderly in Cajazeiras County, PB.

Method: descriptive study, exploratory, cross-sectional, of quantitative approach. A random sample totaled in 348 elderly assisted by Family Health Strategy ,FHS at Cajazeiras County, PB. For the analysis, it was used a statistical package, the Statistical Package for Social Sciences, descriptive simple statistics (frequency/percentage).

Results: There was a high prevalence of hypertension (73.9\%), there was a predominance of males (77.3\%), higher incidence of hypertension among the elderly aged $\leq 71(75.0 \%)$, live in rural areas $(79.2 \%)$, live with his/her partner (77.4\%) and income $\leq 1$ minimum wage (76.1\%).

Conclusion: Health professionals, especially nurses, should understand the limitations and disabling aspects faced by the elderly, preventing proper treatment of hypertension and satisfactory lifestyle to disease prevention and health promotion, creating strategies to mitigate or remedy these difficulties.
1 Nurse from the Federal University of Campina Grande, UFCG, Master in Public Health.

2 Professor at the Federal University of Campina Grande, Academic Unit of the Technical Nursing School, Cajazeiras, Paraíba, Brazil.

3 Academic Unit of Life Sciences, Teacher Training Center; Teaching and Research Manager at the Júlio Bandeira University Hospital, Federal University of Campina Grande (HUJB/UFCG/ EBSERH), Cajazeiras, Paraíba, Brazil.

4 Professor at the Federal University of Campina Grande, Academic Unit of Exact Sciences and Nature, Cajazeiras, Paraíba, Brazil.

5 Nurse by the Federal University of Campina Grande, UFCG, Specialist in Urgency and Emergency.

6 Nurse by the Federal University of Campina Grande, UFCG, Master in Public Health.

7 Nurse Teacher of the Patos Integrated College-FIP.

8 Nurse by Federal University of Paraíba, UFPB, Specialist in Administration of Health and Nursing Services.

9 Nurse. Master in Nursing at the Federal University of Paraiba, Bachelor Professor of Nursing course at FIP, PB, Brazil.

10 Nurse Specialist in Emergency Department, PB, Brazil.

11 Postdoctoral fellow in pediatric dentistry at the Federal University of Minas Gerais. associate professor at the State University of Paraiba Professor of the Post -Graduation in Public Health. PB, Brazil.

Contact information:

\section{Betânia Maria Pereira dos Santos}

” betaniamps@hotmail.com 


\section{Introduction}

The aging of the population is accelerating worldwide. In Brasil, we can observe this process, as shown by data from the Brazilian Institute of Geography and Statistics - IBGE. Comparing the last two censuses (2000 and 2010), it is noticed a significant increase in the elderly population. These, in the year 2000, showed 14.5 million of Brazilians aged above 60 years, which corresponded to $8.6 \%$ of the total population of the country [1].

Actually, Brazil has more than 20.5 million people over 60 years of age, which represents more than $10 \%$ of brazilian population. The numbers show that the aging of brazilian population is due, mainly, to two factors: the reflection of the increase in life expectancy, due to expansion of assistance in health and reducing of the birth rate. There is a projection for 2025 of about 30 million elderly [1].

Aging is a natural process, multifactorial, featuring a man's life stage and occurs by physical, psychological and social changes. In this sense, the World Health Organization (WHO) defines chronologically the elder, one with 60 years or more, in developing countries [2].

It is seen in our environment, poor health conditions of elderly people and the risk of developing cardiovascular diseases, portraying, in this sense, serious problems in this population. In that spite, cardiovascular diseases are the main causes of high mortality rates, and can cause total or partial disability. [3] Among these diseases, we can highlight the systemic arterial hypertension (SAH), focus of our research, it is defined as a multifactorial clinical condition characterized by high and sustained levels of blood pressure [4].

The discovery and monitoring of hypertension, early, are of paramount importance for quality intervention, noting that several risk factors may threaten the health of the elderly and, therefore should be controlled effectively, contributing to the direction of efforts to build a decent future, so that they can enjoy a full and satisfying life that is closely linked to the quality of life of the elderly.

Quality of life becomes a global concern and is considered by scholars a challenge for those who look for ways that can be implemented in daily life, in order to point suggestions in search of good results. The concept of quality of life, according to the World Health Organization (WHO), is related to "the individual's perception of his integration into life in the context of culture and value systems in which they live and in relation to their goals, expectations, standards and concerns"[5].

Thus, the objectives were to determine the prevalence of systemic arterial hypertension and identify the socio-demographic situation of the elderly as a risk factor for systemic arterial hypertension in the city of Cajazeiras, Paraíba, Brasil.

\section{Material and Method}

This is an exploratory and descriptive, cross-sectional survey with a quantitative approach, carried out in the homes of the elderly, located in the city of Cajazeiras-PB. This cityof high backlands of Paraiba is located $477 \mathrm{~km}$ from the capital - João Pessoa-PB, covers an area of $565.8 \mathrm{~km}^{2}$. Amounts to a total population of 58,446 inhabitants, 27,938 men and 30,508 women [1].

As for the quantitative approach, it is used statistical techniques, numerical information and larger samples for classification and analysis of the research, assessing the importance, the risk, severity, and the propensity to diseases and threats by measuring [6].

There were considered the elderly enrolled in the Family Health Strategy-ESF, recorded in the 15 Basic Units of the ESF, distributed in the field and in the urban area of the municipality of Cajazeiras-PB. The population of this research consisted of 10,050 elderly enrolled in the Information System of Primary Care - ISPC of the City of Cajazeiras-PB. However, in 2014 the updated data of the elderly population 
in the city were 10,964, with 4,710 men and 6,254 women. There were randomly selected 371 elderly, and the sample obtained was 348 elderly. As inclusion criteria, the elderly were considered with age $\geq 60$ years, both genders, not institutionalized, attended by the FHS in the city of Cajazeiras, PB and agreed to participate in the study by signing the Free and Informed Consent Term - IC.

This research is part of a doctoral thesis entitled: Prevalence of Metabolic Syndrome in Elderly at a municipality in Northeast Brazil. Was approved by the Ethics Committee of the University Hospital Alcides Carneiro at Federal University of Campina Grande-PB, case number 20111509-037, dated in November 4, 2011 [7].

The technique for data collection was the interview. The instrument was a socio-economic-demographic questionnaire, containing questions about age, gender, marital status and family income. It was measured and recorded PAS. The period of data collection was from November 2011 to May 2012. Initially, the home visit was scheduled for signing the consent form, application of sociodemographic questionnaire and BP measurement. After application of sociodemographic questionnaire was measured BP with a sphygmomanometer aneroid, previously calibrated, with cuff $12 \times 23 \mathrm{~cm}$ and, for obese seniors, $17 \times 32 \mathrm{~cm}$. Measurements were obtained in a sitting position, after rest period of at least twenty minutes and with an empty bladder. They were carried out at least two measurements with a minimum interval of one to two minutes between them. Finally, it was considered the mean of the two measurements.

Data were organized and tabulated in a spreadsheet in Microsoft Office Excell 2007 program, analyzing the variables statistically. For the analysis, it was used Statistical Package for Social Sciences (SPSS), version 17.0. To study the correlation between the variables, it was used the relative risk (RR), a hypothesis test.

\section{Results}

\section{Sociodemographic Characteristics of the Elderly Investigated}

It is observed in Table 1, the high prevalence of hypertension (73.9\%) among the surveyed elderly. In this study was higher the elderly female percentage (66\%). The merits of the elderly prevailed urban area, with $79.3 \%$. About marital status (with partner and unmarried) and income ( $<1 \mathrm{MW}$ and $>$ $1 \mathrm{MW}$ ) the percentages found in two subcategories of each of these 2 variables were practically equivalent No significant percentage differences between the groups. We emphasize that the maximum income found was to be up to three times the minimum wage and the minimum was less than the minimum wage.

Table 1. Characterization of elderly $(n=348)$ as the SAH and sociodemographic data in the city of Cajazeiras, Paraíba, 2011-2012.

\begin{tabular}{l|c|c|}
\multicolumn{1}{|c|}{ Characteristics } & $\mathbf{n}$ & $\%$ \\
\hline With SAH & 257 & 73.9 \\
\hline $\begin{array}{l}\text { Gender } \\
\text { Female }\end{array}$ & 229 & 66.0 \\
\hline Age & \multicolumn{1}{c}{} \\
\hline$\leq 71$ & 188 & 54.0 \\
\hline Residence & & \\
\hline Urban & 276 & 79.3 \\
\hline Spousal situation & & \\
\hline with companion & 177 & 50.9 \\
\hline Income & & \\
\hline$>1$ MW & 189 & 54.3 \\
\hline
\end{tabular}

Source: Research data, 2012. Note: Wages (SM) current: $R \$ 512.00$

Forward to the findings, it was done the association of relative risk (RR) of sociodemographic data for the presence or absence of hypertension, in the investigated elderly, as expressed in Table 2.

By association, we realize that hypertension was more prevalent in elderly group of male $(77.3 \%)$. As for age, those aged $\leq 71$ years had a percentage of $75 \%(n=141)$. 
Table 2. Risk of socio-demographic data for the occurrence of hypertension in 348 elderly residents in the city of Cajazeiras, Paraíba, 2011-2012.

\begin{tabular}{|c|c|c|c|c|c|}
\hline \multirow{3}{*}{$\begin{array}{c}\text { Sociodemographic } \\
\text { data }\end{array}$} & \multicolumn{4}{|c|}{ SAH } & \multirow{3}{*}{$\begin{array}{l}\text { RR } \\
\%\end{array}$} \\
\hline & \multicolumn{2}{|c|}{ Yes } & \multicolumn{2}{|c|}{ No } & \\
\hline & $n$ & $\%$ & $n$ & $\%$ & \\
\hline \multicolumn{6}{|l|}{ Gender } \\
\hline Male & 92 & 77.3 & 27 & 22.7 & 0.93 \\
\hline Female & 165 & 72.1 & 64 & 27.9 & 66.0 \\
\hline \multicolumn{6}{|l|}{ Age (years) } \\
\hline$\leq 71$ & 141 & 75.0 & 47 & 25.0 & 0.97 \\
\hline$>71$ & 116 & 72.5 & 44 & 27.5 & 66.0 \\
\hline \multicolumn{6}{|l|}{ Residence } \\
\hline Rural & 57 & 79.2 & 15 & 20.8 & 0.91 \\
\hline Urban & 200 & 72.5 & 76 & 27.5 & 66.0 \\
\hline \multicolumn{6}{|l|}{ Spousal situation } \\
\hline with companion & 137 & 77.4 & 40 & 22.6 & 1.1 \\
\hline No companion & 120 & 70.2 & 51 & 9.8 & 66.0 \\
\hline \multicolumn{6}{|l|}{ Income } \\
\hline$\leq 1 \mathrm{MW}$ & 121 & 76.1 & 38 & 23.9 & 1.1 \\
\hline$>1 \mathrm{MW}$ & 136 & 72.0 & 53 & 28.0 & 66.0 \\
\hline
\end{tabular}

Source: Research data, 2012. Note: Current Minimum Wages (MW): R\$ 512.00. RR: Relative Risk

When compared the occurrence of hypertension among older adults living in urban and rural areas, there was a higher percentage among rural residents (79.2\%). When analyzed the marital status, was observed that elderly living with their spouse (77.4\%) had higher incidence of hypertension compared to elderly without companions (Table 2). However, in this study, the presence of companion presented himself as a risk factor for hypertension ( $R R=1.1)$, and is considered a weak association (Table 2).

It was found also that SAH was prevalent in the elderly group with family income $<1 \mathrm{MW}$ (76.1\%). Result that, as $R R=1.1$, this socio-demographic variable was presented as a risk factor for hypertension, but considered a weak association (Table 2).

\section{Discussion}

Blood pressure has its own physiology of aging, the systolic and diastolic components gradually increase in both sexes. The causal factors of primary hypertension are due to dysfunction of the autonomic nervous system, dysfunction of the renin-angiotensin-aldosterone system, genetic variations in renal sodium reabsorption and insulin resistance. While in the secondary hypertension, the most common causes are the feocrocitoma, hyperthyroidism and hypothyroidism, chronic renal disease, among others. In women, besides these causes, one of the main reasons to submit more cardiovascular problems than men is hormone reduction characteristic of menopause, because they lose estrogen protection, a hormone that helps protect the arteries. [8]

It should be noted that the increased feminization of old age is an ongoing process. With the advent of modern life, evidenced by urbanization and industrialization, the patriarchal model has been transformed, in addition to women's entry into the labor market. Thus, "there are in the world about 302 million of women and 247 million of men aged 60 or older, making it clear that is occurring a predominance of women, a phenomenon that has been called the "feminization of old age". On average, women live about 7 years longer than men "[9].

In the analysis of sociodemographic characteristics, we found that over $70 \%$ of the elderly were women. In addition, the elderly in general did not have white skin and little schooling (illiterate or incomplete primary education), suggesting an unfavorable socioeconomic situation. They didn't lived alone and had the retirement as the main source of income. This reflects the reality of many developing countries, where the percentage of elderly people who live with son remains high, even with increased longevity [10].

According to the guidelines of the Brazilian Society of Hypertension, the overall prevalence of hypertension between men and women is similar, although it is higher in men up to 50 years, rever- 
sing from the 5th decade. Most research points to a higher prevalence of hypertension in elderly men. It can make this association because men are more exposed to risk factors (smoking, alcohol, obesity, among others), but these results are not conclusive given that the number of women who are also exposed to these factors is increasing [4].

The findings of higher prevalence of male elderly are in line with the research, in that the prevalence of hypertension was higher among elderly men [11-12].

The results for the highest percentage of elderly aged $\leq 71$ years are contrary to those expressed by the Brazilian Society of Cardiology that, in 2010, recorded a prevalence of $75 \%$ of $\mathrm{SAH}$ in individuals over 70 years. The BP elevations are observed during the life cycle, and in people over 60 years, the prevalence of developing hypertension is $60 \%$. With aging, changes occur in the cardiovascular physiology and anatomy, even in the absence of the disease, which increase blood pressure [13]. However, in this study the prevalence of hypertension was nearly equivalent in the 2 age groups surveyed, with a greater tendency for the younger age (Table 2).

The highest levels of AP among older people there is evidence that not only is the age is an impediment to the maintenance of adequate blood pressure figures. Research conducted in India showed that there are elderly populations that are isolated and have low levels of SAH, as is the case of women who live in remote rural areas inmates [14].

This fact led the authors to consider that factors such as urbanization and modern lifestyle can exert more influence in controlling the disease than properly the age [15].

The highest percentage among elderly residents of rural zone contradicts studies that highlighted high rates for elderly residents in urban centers. However, it is known that the farmer still needs further monitoring by the ESF, given the lack of information on symptoms and treatment of hypertension, and also the lack of knowledge of risk fac- tors that aggravate this pathology in the elderly. Although, it should be noted that the habits and customs of the rural worker are increasingly closer to the urban man, considering the strong influence of globalization and mass communication vehicles, which are present in peasant culture.

It was found by the authors a consistent association between the incidence of hypertension and also of other diseases with characteristics indicative of an unfavorable socioeconomic condition, such as non-white skin color, low education, birth in rural areas and lack of health insurance. [10] In Brazil still prevailing disparities for health conditions according to the socioeconomic extract of the elderly. The self-reported health conditions are actually worse in those with of lowest income, reporting impaired mobility and inability to perform activities of daily living [16].

Regarding to marital status, the findings of this study corroborate the results found by research that found a higher prevalence of hypertension among older adults with partners (65.1\%). To assume that there is an influence of the marital status of the elderly and the fact of whether or not hypertension needs to be investigated other factors that are associated with this, such as health, eating habits and lifestyle of the partner. However, the monitoring by the companion is very important for the treatment of hypertension in the elderly, as their presence contributes from the supervision of medication to the sense of protection, security of having someone you trust at your side.

Income is an aspect that directly influences the control of hypertension, since taking the elderly to sufficient financial means to bear the expenses for their support and maintenance of health, the chances for disease control are higher compared to the one that that does not have how to keep themselves. It is known that the Federal Government has been implementing policies of promoting the health of the elderly, with regard to control of hypertension, because the drugs used for treatment 
are distributed free to those proven to certify this condition, but looks even ignorant regarding information, search and monitoring of the elderly by the Family Health Strategy team [3].

A study conducted in northeastern Brazil, with 135 individuals with hypertension, assisted by APS, showed that respondents showed increased BP normalization (28.9\% to $57.0 \%$ of controlled hypertensives) after the ESF mutiprofessional team's performance and after the inclusion of the patient and his family in the design of the proposed treatment, showing how much the assistance of the ESF professionals, shared with family members, can be efficient. Therefore, it is imperative the reorganization of primary care, based on the integration of a multidisciplinary team with the chronically ill and their families, each one with their defined responsibilities, rights and duties [17]. However, the care with food, with the overall health of the elderly, in conducting periodic tests require a greater allocation of income, which seems impossible for one who has a lower income than or equal to the minimum wage.

In Brazil, it has been shown that adults with hypertension, who participate in education programs for health, since they are multidisciplinary, structured and effective, show a significant improvement in health conditions, both with regard to the reduction of risk factors, such as the adherence to the treatment established [18]. Moreover, a study asserts that educational interventions, carried out by the health team, produce significant behavioral changes in patients, though such actions are not easy to implement, because they depend on factors such as: the method used and the interaction of the staff itself with the subjects and their families. [19]

In this research, it was found that gender, age and residence are not risk factors for the occurrence of hypertension, since the RR was less than 1 (one). The fact that the variables of marital situations and income have been presented as risk factors for hypertension, deserves further investigation of these, related to other factors, since the RR was found between 1 and 1.5 , stating that the probability of risk can be no causal [20].

\section{Conclusions}

All statements described throughout this analysis show that the studies of hypertension through the sociodemographic characteristics are still incomplete, and that there is a need that other factors, particularly social and lifestyle are investigated regarding the risk for the occurrence of this disease.

Health professionals should understand the limitations and disabling aspects faced by the elderly, preventing proper treatment of hypertension and satisfactory lifestyle to disease prevention and health promotion, creating strategies to mitigate or remedy these difficulties and minimize the occurrence of hypertension in this age group. It is a challenge for these professionals, who must be trained in receiving the elderly more effectively, through common guidelines, educational groups and home care.

\section{References}

1. Brazil. IBGE. Brazilian Institute of Geography and Statistics. Population Statistics / Sense 2000/2010.

2. WHO. The role of physical activity in healthy aging. Brasilia: World Health Organization, 2006.

3. Brazil. Ministry of Health. Department of Health Care. Department of Primary Care. Systemic Arterial Hypertension. Basic Attention notebooks, n. 15, Brasília - DF, 2013.

4. SBH (Brazilian Society of Hypertension). Brazilian Guidelines on Hypertension VI. Hypertension Journal. 2010; 13 (1).

5. DMS Tavares et al. Quality of life of older people with and without hypertension. Rev. Electronic Nursing. 2011; 13 (2): 438-444

6. Marconi MA, Lakatos .M. Basics of Scientific Methodology. 7th ed. São Paulo: Atlas, 2010

7. Santos, G. E. O. Sample calculation: online calculator.

8. Brazilian Consensus of Hormonal Menopause Therapy - Brazilian Association of Climacteric (Sobrac) - Sao Paulo: Medical Reading, 2014.

9. Nicodemo D, Godoi, M P. Youth of 60-70 years aging: case study on the feminization and older women rights. Rev. Ciênc Ext 2010..; 6 (1): 40-53. 
10. Camargos MCS, Rodrigues RN, Machado CJ. Elderly, family and home: a narrative review of the decision to live alone. Rev Bras Popul Estud 2011; 28 (1): 217-230.

11. Massa KHC. et al. Practice and Physical Activity in Four Areas in Elderly Patients with Hypertension Referred in São Paulo City: population-based study. Rev. Bras. Ativ. Phys. and Health 2012.; 17 (1): 7-13.

12. Brindela P et al. Prevalence, awareness, treatment, and control of hypertension in the elderly: the Three City study for the $3 \mathrm{C}$ Study Investigators. J. Hypertension. 2006; 21: 51-58.

13. Mendes R, JLT Barata. Aging and Blood Pressure. Acta Med. Eng. 2008; 21 (2): 193-98.

14. Gupta R, Pandey RM, Misra A, Agrawal A, Misra P, Dey S. High prevalence and low awareness, treatment and control of hypertension in Asian Indian women. J Hum Hypertens. 2012; 26: 585-93.

15. Barreto MS, LM Matsuda, Marcon SS. Factors associated with inadequate blood pressure control in primary care patients. Esc. Anna Nery. 2016; 20 (1): 114-120.

16. Lima-Costa MF, Facchini LA, DL Matos, Macinko J. Changes in ten years of social inequalities in health among Brazilian elderly (1998-2008). Rev Public Health 2012; 46 (Suppl.): 100-107.

17. Maciel KF, Ulbrich EM, Labronici LM, Maftum MA, Mantovani MF, Mazza VA. Hypertension in the perception of their carriers. Cienc. Nursing. Cheers. 2011; 10 (3): 437-3.

18. Serafim TS, Jesus ES, Pierin AMG. Influence of knowledge on healthy lifestyle in the control of hypertensive. Acta Paul. Enferm. 2010; 23 (5): 658-64.

19. Silva FVF, Silva LF, Guedes MVC, Moreira TMM, Rabelo ACS, Ponte KMA. Nursing care for people with hypertension based on Parse's theory. Esc. Anna Nery. 2013; 17 (1): 111-9.

20. Rothman, et. al. Modern epidemiology. Porto Alegre: Artmed 2011.

Publish in International Archives of Medicine

International Archives of Medicine is an open access journal publishing articles encompassing all aspects of medical science and clinical practice. IAM is considered a megajournal with independent sections on all areas of medicine. IAM is a really international journal with authors and board members from all around the world. The journal is widely indexed and classified Q2 in category Medicine. 